\title{
Compliance with Infection Control Practices among Dental Interns in Alexandria, Egypt
}

\author{
Hashem Hassouna $^{1}$, Mervat El Saygh ${ }^{2}$, Gihan EL Batouti ${ }^{3}$ \\ ${ }^{1}$ Department of Oral Maxillofacial Surgery, Faculty of Dentistry, Pharos University in Alexandria, Alexandria, \\ Egypt. \\ ${ }^{2}$ Microbiology and Immunology Laboratory, Alexandria Main University Hospital, Alexandria, Egypt. \\ ${ }^{3}$ Department of Microbiology and Immunology, Faculty of Pharmacy, Pharos University in Alexandria, \\ Alexandria, Egypt. \\ Corresponding Author: Gihan EL Batouti
}

\begin{abstract}
Background: Dental settings pose a crucial risk for the transmission of infections for both dental healthcare providers and their patients. The risk of occupational exposure includes parenteral and respiratory droplet transmission. In order to minimize the risk of cross infection in dental settings, standard infection control precautions should be followed. This study aimed to assess the compliance with infection control practices among dental interns in Alexandria, Egypt.

Methods: The study included 220 dental interns (122 males and 98 females) from different dental settings in Alexandria. A questionnaire was distributed to public and private sectors.

Results: Regarding compliance to personal protective equipment, a $100 \%$ adherence to wearing gloves was found. Moreover, $54.3 \%$ of males and $45.7 \%$ of females always wore masks, but only $27.7 \%$ of them wore eye protection during dental procedures. The majority performed hand hygiene after doffing gloves, $69.5 \%$ but only $19.1 \%$ performed both before donning and after doffing gloves. The occurrence of needle stick injuries was $46.4 \%$ from surgical procedures and $36.4 \%$ from nonsurgical procedures. A $90.0 \%$ properly disposed of sharps, while only $24.5 \%$ used the scoop technique for recapping. Only $43.2 \%$ interns completed their Hepatitis B vaccination schedule, from which $52.6 \%$ undergone antibody testing.

Conclusion: Our study showed that the overall practice of infection-control measures among dental interns in Alexandria was good. Sharps safety regulations, completing HBV vaccination, and antibody post testing need more emphasis. Continuous educational training programs and follow up assessments should be implemented to maximize the compliance of dental healthcare providers.
\end{abstract}

Key Words: Dental interns, Hepatitis B virus Immunization, infection control practices, needles stick injuries, personal protective equipment.

\section{INTRODUCTION}

Dental settings pose a crucial risk for the transmission of infections ${ }^{[1,2]}$. The risk of occupational exposure is based mainly upon the prevalence of blood borne viruses in patients, the direct and indirect contact with blood and body fluids including parenteral routes of transmission as well as the inhalation of droplet or airborne pathogens ${ }^{[3]}$. These pathogens include cytomegalovirus, hepatitis- $\mathrm{B}$ and $\mathrm{C}$ virus
(HBV and HCV), Herpes simplex virus types 1 and 2, human immunodeficiency virus (HIV), Mycobacterium tuberculosis, streptococci, and severe acute respiratory syndrome (SARS) virus ${ }^{[1,3]}$.

Dental healthcare personnel (DHCP) may contract blood borne infections via accidental needle stick injuries during surgical procedures or anesthesia injections. On the other hand DHCP have the potential to transmit infection to their 
Hashem Hassouna et.al. Compliance with infection control practices among dental interns in Alexandria, Egypt.

patients and thereby to others in the community ${ }^{[4]}$.

In order to minimize the risk of cross infection in dental settings the Centers for Disease and Control (CDC) issued specific guidelines that provide recommendations to ensure the safety of DHCP and their patients [1]. These recommendations include the implementation of standard precautions with emphasis on hand hygiene, the use of barrier techniques as personnel protective equipment (PPE), sterilization of dental instruments, environmental cleaning and disinfection as well as immunization against HBV ${ }^{[1,2]}$. This study aimed to assess the compliance with infection control practices among dental interns in Alexandria, Egypt.

\section{MATERIAL AND METHODS Questionnaire}

A questionnaire based crosssectional study was adopted. The study included 220 dental interns (122 males and 98 females) with ages ranging from 22- 26 years (mean age of 24). A questionnaire was distributed to dental interns in different dental settings in Alexandria, Egypt for a 3 months period during the COVID-19 pandemic in 2020.

The questionnaire comprised of 16 closed ended questions regarding gender, age, hand hygiene, personal protective equipment (PPE), sharps safety and immunization data. Participation in this study was entirely voluntary and it was emphasized that confidentiality would be maintained.

\section{HBV antibody testing}

HBV antibody testing was performed for the dental interns that had completed their three dosage vaccination and agreed to undergo the test. HBV antibody testing was conducted according to manufacturer's instructions using Human Anti-HBV surface Antigen Antibody (AntiHBV) ELISA Kit (MyBioSource, MBS9304959). It is a sandwich enzymelinked immunosorbent assay (ELISA) that detects Anti-HBVSAg in human serum ${ }^{[5]}$.

\section{Statistical Analysis}

The collected data was statistically analyzed using IBM SPSS software package Version 20.0 (Armonk, N.Y, USA: IBM Corp). The Kolmogorov- Smirnov was used to verify the normality of distribution of variables. Comparisons between groups for categorical variables were assessed using Chi-square test (Fisher's Exact correction). Significance of the obtained results was judged at the $5 \%$ level.

\section{RESULTS}

A total of 220 dental interns participated in this study; 122 males and 98 females whose ages ranged from 22 to 26 years. The compliance to using PPE was reported for, gloves, masks, and goggles or face shield (Table1).

\begin{tabular}{|c|c|c|c|c|c|}
\hline PPE Used & Male No. ( \%) & Female No. ( \%) & Total No. ( \%) & $\chi^{2}$ & $\mathbf{p}$ \\
\hline \multicolumn{6}{|l|}{ Gloves } \\
\hline Always & $122(55.5)$ & $98(44.5)$ & $220(100)$ & \multirow{3}{*}{-} & \multirow{3}{*}{-} \\
\hline Occasionally & $0(0)$ & $0(0)$ & $0(0)$ & & \\
\hline Never & $0(0)$ & $0(0)$ & $0(0)$ & & \\
\hline \multicolumn{6}{|l|}{ Masks } \\
\hline Always & $114(54.3)$ & $96(45.7)$ & $210(100)$ & \multirow{3}{*}{2.555} & \multirow{3}{*}{$\begin{array}{l}{ }^{\mathrm{FE}} \mathrm{p}= \\
0.191\end{array}$} \\
\hline Occasionally & $8(80)$ & $2(20)$ & $10(100)$ & & \\
\hline Never & $0(0)$ & $0(0)$ & $0(0)$ & & \\
\hline \multicolumn{6}{|c|}{ Goggles/ Face shield } \\
\hline Always & $16(26.2)$ & $45(73.8)$ & $61(100)$ & \multirow{3}{*}{29.377} & \multirow{3}{*}{$<0.001^{*}$} \\
\hline Occasionally & $68(68.0)$ & $32(32.0)$ & $100(100)$ & & \\
\hline Never & $38(64.4)$ & $21(35.6)$ & $59(100)$ & & \\
\hline
\end{tabular}

A $100 \%$ adherence to wearing gloves during dental procedures was recorded in both males and females. A total of 210 dental interns; 114 males $(54.3 \%)$ and 
Hashem Hassouna et.al. Compliance with infection control practices among dental interns in Alexandria, Egypt.

96 females (45.7\%) always wore masks, while only 10 dental interns $(80.0 \%$ males and $20.0 \%$ females) wore them occasionally. As for goggles or face shields; a significant statistical difference was recorded for wearing eye protection where 61 dental interns always wore them (26.2\% of males and $73.8 \%$ of females), 100 occasionally wore them $(68.0 \%$ of males and $32.0 \%$ of females) and 59 dental interns who never wore eye protection. (64.4\% of males and $35.6 \%$ of females).

The number of dental interns that complied to hand hygiene before donning gloves was only $25(11.4 \%)$, while the majority performed hand hygiene after doffing gloves, 153 (69.5\%) and 42 (19.1\%) both before donning and after doffing gloves. Moreover, 171 (77. 7\%) changed gloves between patients, while 49 (22.3\%) did not. A total of $214(97.3 \%)$ reported to have properly disposed of their contaminated PPE in biohazard labelled waste bags, and only $6(2.7 \%)$ discarded them in non- biohazard regular waste.

Regarding sharps safety, the occurrence of needle stick injuries among the total 220 dental interns was $102(46.4 \%)$ from surgical procedures and $80(36.4 \%)$ from non- surgical procedures. The difference between these results were found to be statistically significant with a $\mathrm{p}<$ 0.033(Table2).

As for sharps disposal; 198 (90.0\%) properly disposed of used needles in the designated puncture-proof sharp boxes, while 22(10.0\%) did not. Recapping of anesthesia needle was improperly performed using both hands by the majority of interns comprising 166 (75.5\%), while 54 (24.5\%) used the one hand -scoop technique for recapping sharps.

Table 2: Occurrence of Needle stick Injuries Among the 220 Dental Interns According to the Dental Procedures

\begin{tabular}{|c|c|c|c|c|c|}
\hline Dental Procedures & $\begin{array}{l}\text { Needle stick } \\
\text { injuries } \\
\text { No. }(\%) \\
\end{array}$ & $\begin{array}{l}\text { No Needle stick } \\
\text { injuries } \\
\text { No. }(\%) \\
\end{array}$ & Total No. (\%) & $\chi^{2}$ & $\mathbf{p}$ \\
\hline Non- Surgical Procedures & $80(36.4)$ & $140(63.6)$ & \multirow{3}{*}{$220(100)$} & \multirow{2}{*}{$4.535^{*}$} & \multirow{2}{*}{0.033} \\
\hline Surgical Procedures & $102(46.4)$ & $118(53.6)$ & & & \\
\hline Total No. (\%) & $182(41.4)$ & $258(58.6)$ & & & \\
\hline
\end{tabular}

p: $p$ value for comparing between Needle stick injuries and No Needle stick injuries

*: Statistically significant at $p \leq 0.05$

All dental interns were vaccinated against HBV (Table 3). However, only 95 $(43.2 \%)$ interns completed their vaccination schedule of 3 doses; divided as $48(39.3 \%)$ males to $47(48.0 \%)$ females. Out of the 48 males whom completed their vaccination schedules, only $16(33.3 \%)$ had undergone post- vaccination testing for HBV surface antibody levels. On the other hand, from the 47 females, $34(72.3 \%)$ had undergone testing (Table 4). These results were found to be statistically significant, $\mathrm{p}<0.001$.

\begin{tabular}{l} 
Table 3: Vaccination with Hepatitis B Virus (HBV) Vaccine Among Dental Interns \\
\begin{tabular}{|l|l|l|l|l|l|}
\hline Gender & $\begin{array}{l}\text { Completed Doses with } \\
\text { HBV vaccine No. ( \%) }\end{array}$ & $\begin{array}{l}\text { Did not Complete Doses with } \\
\text { HBV vaccine No. ( \%) }\end{array}$ & $\begin{array}{l}\text { Total } \\
\text { No. ( \%) }\end{array}$ & $\chi^{\mathbf{2}}$ & p \\
\hline Male & $48(39.3)$ & $74(60.7)$ & $122(100)$ & \multirow{2}{*}{1.644} & \multirow{2}{*}{0.200} \\
\hline Female & $47(48.0)$ & $51(52.0)$ & $98(100)$ & & \\
\hline $\begin{array}{l}\text { Total } \\
\text { No. (\%) }\end{array}$ & $95(43.2)$ & $125(56.8)$ & $220(100)$ & & \\
\hline
\end{tabular} \\
\hline
\end{tabular}

Table 4: Hepatitis B Surface Antibody Testing Among the 95 Dental Interns that Completed their Vaccination

\begin{tabular}{|l|l|l|l|l|l|}
\hline Gender & $\begin{array}{l}\text { Test done } \\
\text { No. ( \%) }\end{array}$ & $\begin{array}{l}\text { Test not done } \\
\text { No. ( \%) }\end{array}$ & $\begin{array}{l}\text { Total } \\
\text { No. ( \%) }\end{array}$ & $\chi^{2}$ & p \\
\hline Male & $16(33.3)$ & $32(66.7)$ & $48(100)$ & \multirow{2}{*}{$14.493^{*}$} & $<0.001^{*}$ \\
\hline Female & $34(72.3)$ & $13(27.7)$ & $47(100)$ & & \\
\hline $\begin{array}{l}\text { Total } \\
\text { No. (\%) }\end{array}$ & $50(52.6)$ & $45(47.4)$ & $95(100)$ & & \\
\hline \\
7
\end{tabular}



Egypt.

\section{DISCUSSION}

Infection prevention is a priority in dental practice. Infections can be transmitted by direct and indirect contact in addition to respiratory droplets. Direct contact may be with blood, body secretions and saliva. Indirect contact is through the surrounding contaminated environmental surfaces, devices or instruments ${ }^{[6]}$. It is therefore essential to comply to standard precautions and recommended guidelines in order to prevent cross-infection among dental health-care providers and patients as well as between patients themselves ${ }^{[1,2]}$.

This study aimed to assess the compliance of dental interns to infection control practices as hand hygiene, use of PPE, sharps safety and immunization. Our study included 220 dental interns; 122 males and 98 females from both public and private sectors (institutions and clinics) in Alexandria, Egypt during the COVID -19 pandemic in 2020.

Respiratory droplets and the generation of aerosols of water, saliva, blood, and the presence of microorganisms are common during dental procedures. These droplets may remain suspended in the air for a long time or settle on surfaces or equipment posing as a major source of infection to the surrounding environment in any dental healthcare setting ${ }^{[7,8]}$. In order to minimize the transmission and susceptibility to airborne and blood born infections; it is mandatory that dental care providers always use PPE as gloves, protective gowns, mask, goggles or face shields during any dental procedure ${ }^{[2,9]}$.

In general, the compliance to wearing PPE was very high among both male and female dental interns. A $100.0 \%$ adherence to always wearing gloves, $90.0 \%$ to always wearing masks and only $27.7 \%$ compliance to wearing eye protection or goggles was recorded. Males were found to be more compliant in always wearing gloves and masks, but females showed a much higher percentage of compliance to wearing eye protection $(73.8 \%$ females to $26.2 \%$ males). Lower percentages were observed by Mehasnah et al, ${ }^{[10]}(87.9 \%$ and $78.9 \%)$ and Yadav BK, et al ${ }^{[11]}(90.0 \%)$, regarding the adherence to always wearing gloves and masks respectively. However, Mehasnah et al, ${ }^{[10]}$ reported a higher percentage of compliance to changing gloves between patients $(89.5 \%)$ in comparison with our findings; only $77.7 \%$. The majority of dental interns properly disposed of PPE in the designated biohazard labelled bags (97.3\%), indicating their awareness and practice of proper disposal of biohazardous waste.

Hand hygiene is a crucial practice that prevents the transmission spread of infections any healthcare setting ${ }^{[12,13]}$. We reported that $69.5 \%$ of dental interns performed hand hygiene after doffing gloves, only $11.4 \%$ before donning and $19.1 \%$ both before donning and after doffing. These findings reflect lack the awareness of the importance of performing hand hygiene before donning gloves to prevent its possible contamination and thereby preventing the spread of infection to patients. Much higher percentages were revealed by $\mathrm{Ch} \mathrm{AN}{ }^{[6]}$ et al in Pakistan showed that $79.0 \%$ of the dentists performed hand hygiene before and after contacting patients, while in Saudia Arabia, AlAhdal A, et al ${ }^{[14]}$ reported that $96.7 \%$ and $89.4 \%$ of the dentists performed hand hygiene before and after contacting patients, respectively.

Many dental instruments used in both surgical and non surgical dental procedures could cause needlestick injuries and hence could be a potential source of infection. These procedures include normal extraction, surgical extraction of remaining roots, odonectomy of impacted teeth, and accidental punctures from dental needles during injection of local anaesthesia ${ }^{[15,16]}$. Sharps safety practices and proper biohazard waste management disposal should be strictly implemented and followed. A total of 182 (41.4\%) of dental interns were exposed to needlestick injuries, from which the higher percentage was acquired from surgical procedures $(46.4 \%)$. 
Regarding the proper disposal of sharps; $90.0 \%$ of interns properly disposed of used needles in the designated punctureproof sharp boxes. Similar findings were reported by Mehasnah et al, ${ }^{[10]}(88.4 \%)$ and $99.2 \%$ by AlAhdal et al ${ }^{[14]}$. Recapping of sharps is one of the most important causes of needle stick injuries in healthcare providers. [Only $24.5 \%$ used one hand technique for necessary recapping of sharps in our study. The practice of recapping is prohibited according to standard precautions and sharp safety measures. However, procedures as the reuse of local anaesthesia injection for the same patient are sometimes mandatory. In this case sharp safety guidelines recommend the use of the one hand -scoop technique for recapping sharps [17-19]

HBV is a well-recognized occupational bloodborne biohazard risk for dental care providers. It can be transmitted by their exposure to blood and body fluids of an infected person ${ }^{[10]}$. In Egypt HBV immunization is obligatory for newborns in their vaccination schedule. It has also become mandatory for all healthcare providers including dentists in public and private institutions and settings. In our study all dental interns were vaccinated against HBV. However, only 95 (43.2 \%) interns completed their vaccination schedule of 3 doses. Incomplete dose administration indicates inadequate HBV antibody formation and coverage. Out of the 95 compliant interns; females represented a higher percentage of compliance to taking the 3 doses compared to males; $48.0 \%$ to $39.3 \%$ respectively. Comparable percentages for complete HBV vaccination were found in other studies; in Jordan $(82.1 \%)^{[10]}$, Pakistan ${ }^{[6]}(71.6 \%)$, New Zealand $^{[20]}(94.2 \%)$, and Saudi Arabia ${ }^{[14]}$ $(90.6 \%)$.

Post-vaccination HBV antibody level testing is very important to ensure the presence of a protective antibody level ${ }^{[21]}$. Out of the 95 interns that completed their three vaccination doses, $52.6 \%$ had undergone HBV antibody level testing, from which the majority were females comparing $73.3 \%$. All were found to be responders with an adequate antibody response and coverage.

\section{CONCLUSION}

Our study showed that the overall practice of infection-control measures among dental interns in Alexandria was good and acceptable. The majority of the participants followed the Infection Control Guidelines for Dental Healthcare settings regarding the use of PPE, proper disposal of sharps and biohazard waste and vaccination against HBV. However, there exists a the lack of knowledge and implementation regarding sharps safety as recapping needles and completing HBV vaccination schedule and antibody level post testing. This issue must be well emphasised to ensure occupational safety and prevent the transmission of infection to dentists and their patients in any dental healthcare setting. Continuous educational training programs and follow up assessments should be implemented to maximize the compliance of dental healthcare providers.

Acknowledgement: None

\section{Conflict of Interest: None}

\section{Source of Funding: None}

\section{Ethical Approval: Approved}

\section{REFERENCES}

1. Centers for Disease Control and Prevention. Summary of Infection Prevention Practices in Dental Settings: Basic Expectations for Safe Care. Atlanta, GA: Centers for Disease Control and Prevention, US Dept of Health and Human Services; 2016.

2. Centers for Disease Control and Prevention Interim Infection Prevention and Control Guidance for Dental Settings During the Coronavirus Disease 2019 (COVID-19) Pandemic;2020

3. Tellier R., Li Y, Cowling, BJ. et al. Recognition of aerosol transmission of infectious agents: a commentary. $B M C$ 
Hashem Hassouna et.al. Compliance with infection control practices among dental interns in Alexandria, Egypt.

Infect Dis , $2019 \quad 19, \quad 101$. https://doi.org/10.1186/s12879-019-3707-y

4. Cleveland JL,Gray SK, Harte,JA, et al. J Am Dent Assoc. 2016; 147(9): 729-738. doi:10.1016/j.adaj.2016.03.020

5. Hepatitis B FAQs for Health Professionals. Centers for Disease Control and Prevention.2018. Available online at https://www.cdc.gov/hepatitis/hbv/hbvfaq.ht m\#overview.

6. Ch AN, Usman N, Kiran S,et al . Cross infection control in dental institutions. Pak Oral Dent J. 2018;38(4):419-422.

7. Zemori C, de Soet H, Criellard W, Laheij A. A scoping review on bioaerosols in healthcare and the dental environment. PLoS One. 2017;12:eo178007.

8. World Health Organization. The Top 10 Causes of Death. Available at: who.int/news-room/fact-

sheets/detail/the-top-10-causes-of-death. 2018.

9. Mutters NT, Hägele U, Hagenfeld D, Hellwig E, Frank U. Compliance with infection control practices in an university hospital dental clinic. GMS Hyg Infect Control. 2014;9(3):1-5.

10. Mahasneh AM, Alakhras M, Khabour OF , et al. Practices of Infection Control Among Dental Care Providers: A Cross Sectional Study. Clinical, Cosmetic and Investigational Dentistry 2020:12 281-289.

11. Yadav BK, Rai AK, Agarwal S, Yadav B. Assessment of infection control practice in private dental hospital. Int J Res Med Sci. 2017;5(11):4737-4742. doi:10.18203/23206012.ijrms20174687.

12. CDC .Core Infection Prevention and Control Practices for Safe Healthcare Delivery in All Settings -Recommendations of the HICPAC.2017.

13. Kratzel A, Todt D, V'kovski $\mathrm{P}$, et al. Inactivation of severe acute respiratory syndrome coronavirus 2 by WHOrecommended hand rub formulations and alcohols. Emerg Infect Dis. 2020 Jul [date cited].

https://doi.org/10.3201/eid2607.200915.
14. AlAhdal A, Aljehani W, Ali G, Bayoumi A. Knowledge, attitude and practice of infection control measures in private dental clinics in Jeddah, Saudi Arabia. Int J Dent Oral Health. 2019;5(1):1-6.

15. Tripathi S, Singh RD, Singhal R, et al. Sharps Safety and Management among Dental Practitioners. J Dent Probl Solut.2017; 4(2): 015-018.10.17352/23948418.000041

16. AlDakhil L, Yenugadhati N, Al-Seraihi O. et al. Prevalence and associated factors for needlestick and sharp injuries (NSIs) among dental assistants in Jeddah, Saudi Arabia. Environ Health Prev Med.2019; 24, 60. https://doi.org/10.1186/s12199-019-0815-7

17. CDC.Workbook for Designing, Implementing and Evaluating a Sharps Injury Prevention Program;2008.

18. NHS Employer-Managing the risk of sharps injuries framework. 2015

19. Ganesh N., Chavis S. Safe Handling of Sharps and Safe Injection Practices. In: DePaola L., Grant L. (eds) Infection Control in the Dental Office. Springer, Cham. 2020. https://doi.org/10.1007/978-3-030-300852_8

20. Lamb A, Hong C, De Silva H, Thomson W, Broadbent J. New Zealand oral health practitioners' cross-infection control practices. N Z Dent J. 2019;115(1):5-10.

21. Nagashima S, Yamamoto $\mathrm{C}$, Ko $\mathrm{K}$, et al.Acquisition rate of antibody to hepatitis $\mathrm{B}$ surface antigen among medical and dental students in Japan after three-dose hepatitis B vaccination. Vaccine.2019;37(1) : 145151,ISSN 0264-410X, https://doi.org/10.1016/j.vaccine.2018.11.01 9.

How to cite this article: Hassouna H, Mervat El Saygh, Gihan EL Batouti. Compliance with infection control practices among dental interns in Alexandria, Egypt. Int J Health Sci Res. 2021; 11(6): 66-71. DOI: https://doi.org/10. 52403/ijhsr.20210610 